\title{
ORTHODONTIC TREATMENT ALTERNATIVE TO A CLASS III SUBDIVISION MALOCCLUSION
}

\author{
Guilherme JANSON ${ }^{1}$, José Eduardo Prado de SOUZA², Sérgio Estelita Cavalcante BARROS ${ }^{2}$, \\ Pedro ANDRADE JUNIOR ${ }^{3}$, Alexandre Yudi NAKAMURA ${ }^{2}$
}

\author{
1-DDS, MSc, PhD, MRCDC (Member of the Royal College of Dentists of Canada), Professor and Head, Department of Pediatric Dentistry, Orthodontics \\ and Community Health. Bauru School of Dentistry, University of São Paulo, Bauru, SP, Brazil. \\ 2- DDS, MSc, PhD, Former Orthodontic Graduate Student, Department of Pediatric Dentistry, Orthodontics and Community Health. Bauru School of \\ Dentistry, University of São Paulo, Bauru, SP, Brazil. \\ 3- DDS, Private Practice, São Paulo, SP, Brazil.
}

Corresponding address: Dr. Guilherme Janson - Universidade de São Paulo - Faculdade de Odontologia de Bauru - Departamento de Odontopediatria, Ortodontia e Saúde Coletiva - Alameda Octávio Pinheiro Brisolla 9-75 - 17012-90 - Bauru - SP - Brazil - Business Phone/Fax: 551432344480 - Home Phone/Fax: 551432342650 - e-mail: jansong@travelnet.com.br

Received: January 12, 2009 - Accepted: January 18, 2009

\begin{abstract}
C lass III malocclusions are considered one of the most complex and difficult orthodontic problems to diagnose and treat. Skeletal and/or dental asymmetries in patients presenting with Class III malocclusions can worsen the prognosis. Recognizing the dentoalveolar and skeletal characteristics of subdivision malocclusions and their treatment possibilities is essential for a favorable nonsurgical correction. Therefore, this article presents a nonsurgical asymmetric extraction approach to Class III subdivision malocclusion treatment which can significantly improve the occlusal and facial discrepancies.
\end{abstract}

Key words: Class III malocclusion. Asymmetric extraction. Midline deviation. Nonsurgical treatment.

\section{INTRODUCTION}

Several studies have demonstrated that in a large number of Class II subdivision cases, the maxillary dental midline will be coincidental, or present a minimal deviation to the clinical facial midline while the mandibular dental midline will be displaced towards the Class II side, in faces with subclinical asymmetry $2,7,13,16,18,25$. In such a situation, one of the best treatment options would be the extraction of two maxillary premolars and one mandibular premolar on the Class I side $2,4-6,13,16-18,26$, provided that the patient's profile allows for retraction of the maxillary and mandibular incisors. Correction of dental midline deviation in this treatment approach is facilitated since it is obtained concurrently with space closure of the mandibular arch. Also there is minimal need of intermaxillary elastics for correction of the dental midlines ${ }^{21}$. Although similar studies have not been conducted in dental Class III subdivision cases, an analogous rationale in diagnosis and treatment planning can be applied in these patients, as exemplified in the following case.

\section{Diagnosis and etiology}

A 17-year and 3-month-old girl came for orthodontic treatment to the private orthodontic office of Dr. J.E.P.S. The patient's major reason for seeking treatment was to improve her dental esthetics. Clinical examination showed a slight Class III facial pattern, with slightly strained lip competence. The frontal examination showed a mild subclinical facial asymmetry ${ }^{7}$. Her intraoral examination revealed complete Class III molar and canine relationships on the right side and a Class I on the left side, with anterior and transverse bilateral crossbites. There were $7 \mathrm{~mm}$ of crowding in the maxillary and $5 \mathrm{~mm}$ in the mandibular arches, and the curve of Spee was mild. The mandibular dental midline was coincident to the facial midplane and the maxillary dental midline was deviated to the right (Figures 1 and 2). Cephalometrically, the patient presented a skeletal Class III malocclusion, with an equilibrated growth pattern and with the maxillary and mandibular incisors slighty proclined (Figure 3 and Table 1). The panoramic radiograph showed the absence of the maxillary and mandibular third molars on the left and right sides, respectively (Figure 4). Except for gingival recessions at the mandibular right lateral and central incisors there was sound periodontal support and orthodontic therapy could be normally undertaken. 

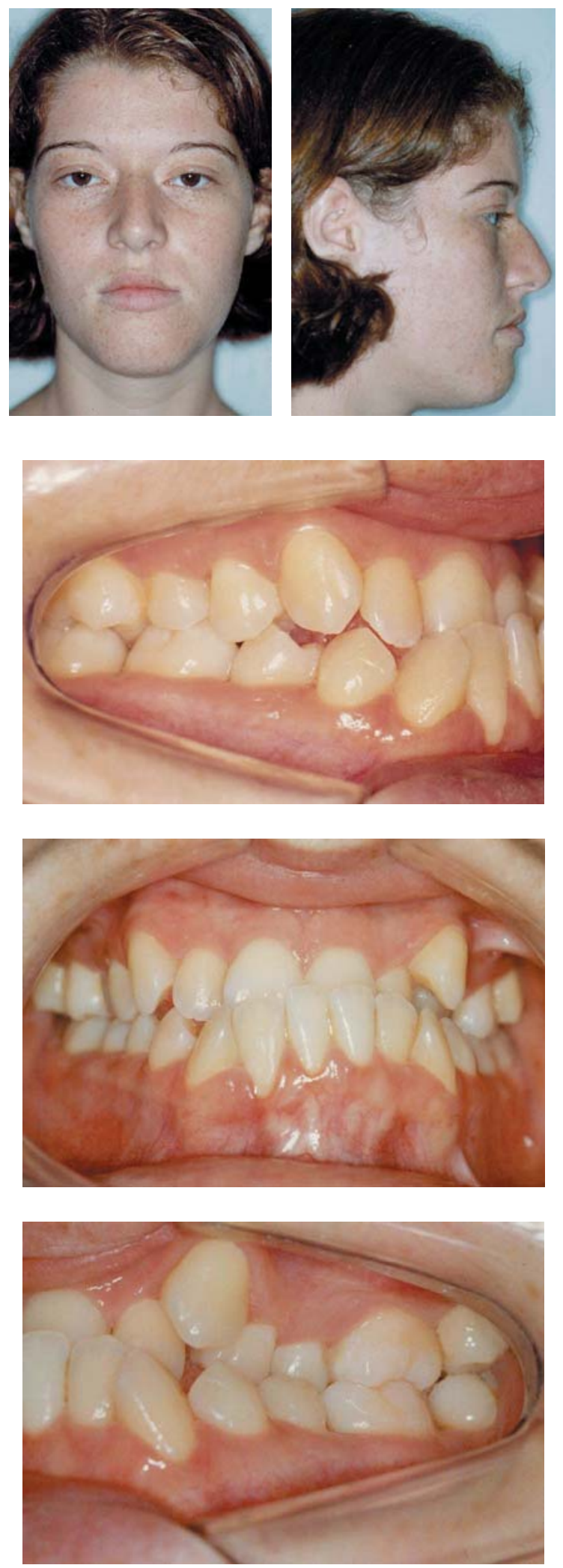

FIGURE 1- Pretreatment facial and intraoral photographs (patient signed informed consent authorizing the publication of these pictures)
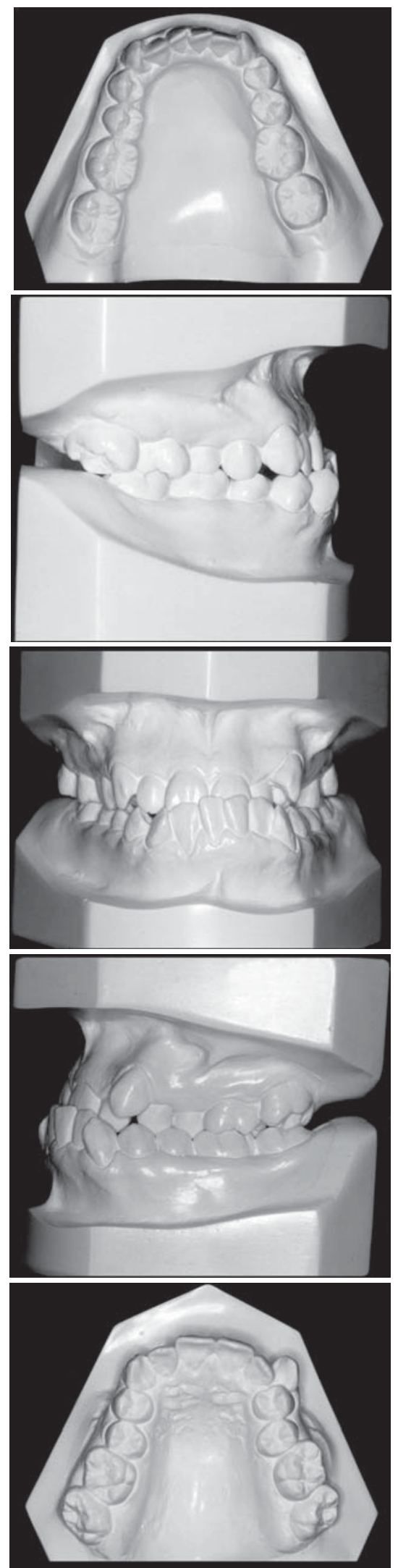

FIGURE 2- Pretreatment study models 


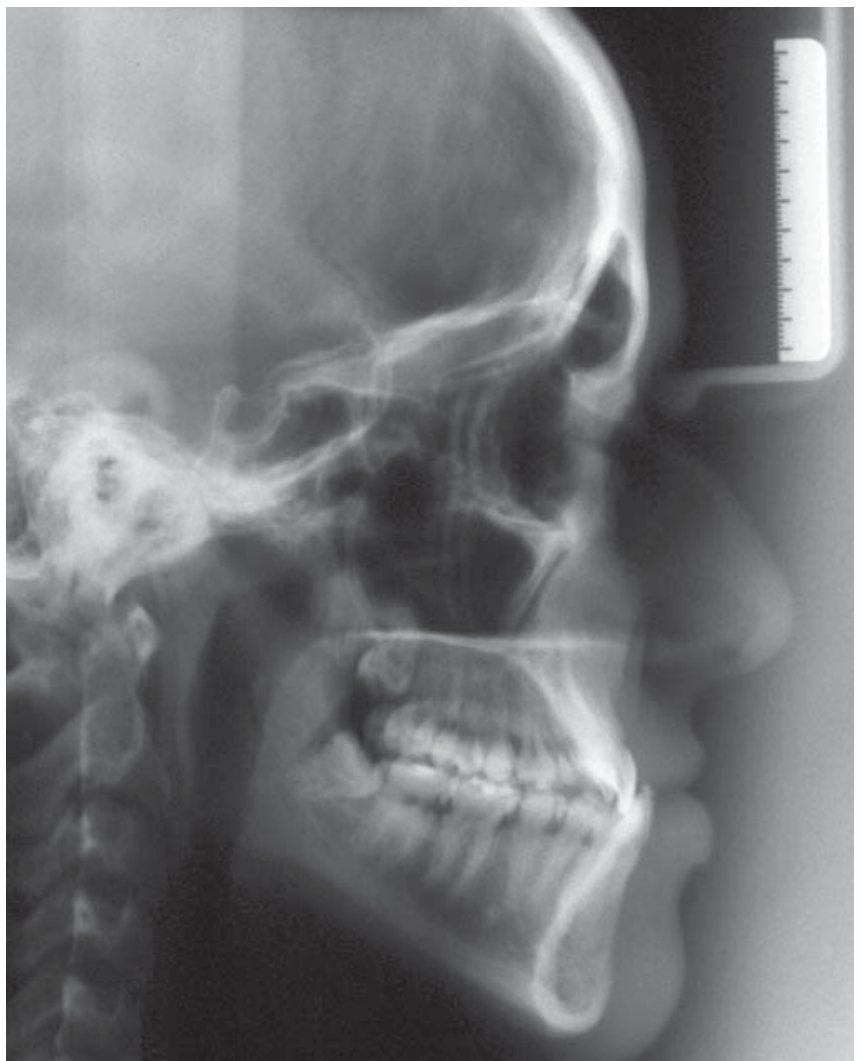

FIGURE 3- Pretreatment cephalometric radiograph

\section{Treatment objectives}

The treatment objectives consisted of correcting the posterior bilateral cross-bite, the anterior crossbite, the maxillary and mandibular crowding, the maxillary to mandibular midline deviation and her lower lip protrusion. These changes would improve her facial esthetics significantly.

\section{Treatment alternatives}

Based on the objectives, three treatment alternatives were possible. Firstly the posterior bilateral cross-bite would be corrected through rapid maxillary expansion (RME) and extraction of two mandibular first premolars and two maxillary second premolars. This option would require great patient compliance in using Class III elastics to correct molar relationship on the Class III side. Secondly, besides RME, treatment would include extraction of four first premolars, followed by surgical maxillary rotation and protraction of the right side. The third option included only slow maxillary expansion and extraction of two mandibular first premolars and the first maxillary premolar on the Class I side. This option would simplify the orthodontic mechanics because molar relationship on the Class III side would remain, while all the other problems would be corrected. Based on the pros and cons of the three alternatives, and on the reluctance of the patient and her parents to undergo surgery, the third option was chosen.

\section{Treatment progress}

The malocclusion was treated with pre-adjusted 0.022 x 0.028-inch slot Biofunctional System (Dentaurum, Pforzheim, Germany). After extraction of the mandibular first premolars, leveling and alignment of maxillary and mandibular arches began with continuous round nitinol wires. The option to postpone extraction of the maxillary left first premolar was to protrude the incisors and help in correcting the anterior and posterior cross-bites with expanded leveling archwires (Figure 5). Concurrently, initial retraction of the mandibular canines was performed with elastic chains, without anchorage reinforcement in the mandibular arch, and anterior intermaxillary elastics, from palatal buttons on the maxillary central incisors to the brackets of the mandibular incisors, were used to correct the anterior crossbite. The Class III bracket system applies lingual crown torque on the maxillary anterior teeth ( 0 degree) and labial crown torque on the mandibular anterior teeth $(+14$ degrees $)$ to counteract Class III elastic effects. The maxillary arch was expanded with increasingly larger and expanded round stainless steel archwires up to 0.020 -inch diameter. After leveling and alignment, with the cross-bites corrected, the maxillary left first premolar was removed and closure of the remaining extraction spaces was performed with stainless steel $0.019 \times 0.025$-inch rectangular archwires. Class III and II elastics were used to coordinate the arches 
TABLE 1- Cephalometrics mesurements

\begin{tabular}{|c|c|c|}
\hline Measurements & Pretreatment & Posttreatment \\
\hline & \multicolumn{2}{|c|}{ Maxillary component } \\
\hline SNA $\left({ }^{\circ}\right)$ & 79.3 & 80.6 \\
\hline A-Nperp (mm) & 3.9 & 5.0 \\
\hline \multirow[t]{2}{*}{ Co-A (mm) } & 86.6 & 86.7 \\
\hline & \multicolumn{2}{|c|}{ Mandibular component } \\
\hline SNB $\left({ }^{\circ}\right)$ & 81.3 & 80.6 \\
\hline P-Nperp (mm) & 10.7 & 11.3 \\
\hline Co-Gn (mm) & 121.0 & 120.1 \\
\hline \multirow[t]{2}{*}{ Co.Go.Me $\left({ }^{\circ}\right)$} & 124.2 & 123.8 \\
\hline & \multicolumn{2}{|c|}{ Maxillomandibular relationship } \\
\hline ANB $\left({ }^{\circ}\right)$ & -2.0 & 0.0 \\
\hline Wits* appraisal (mm) & -7.2 & -4.2 \\
\hline \multirow[t]{2}{*}{ FMA $\left(^{\circ}\right)$} & 22.5 & 21.1 \\
\hline & \multicolumn{2}{|c|}{ Vertical component } \\
\hline SN.GoGn $\left(^{\circ}\right)$ & 33.5 & 32.7 \\
\hline ANS-Me (mm) & 68.5 & 69.8 \\
\hline \multirow[t]{2}{*}{$\mathrm{PFH}: \mathrm{AFH}^{*}(\%)$} & 81.9 & 81.3 \\
\hline & \multicolumn{2}{|c|}{ Maxillary dentoalveolar component } \\
\hline $\mathrm{Mx} 1 . \mathrm{NA}\left({ }^{\circ}\right)$ & 30.0 & 30.0 \\
\hline \multirow[t]{2}{*}{ Mx1-NA (mm) } & 4.7 & 5.3 \\
\hline & \multicolumn{2}{|c|}{ Mandibular dentoalveolar component } \\
\hline Md1.NB $\left({ }^{\circ}\right)$ & 26.9 & 18.1 \\
\hline Md1-NB (mm) & 4.7 & 2.5 \\
\hline \multirow[t]{2}{*}{$\operatorname{IMPA}\left({ }^{\circ}\right)$} & 88.4 & 80.8 \\
\hline & \multicolumn{2}{|c|}{ Maxillary/mandibular incisors } \\
\hline Mx1.Md1 $\left({ }^{\circ}\right)$ & 121.5 & 133.0 \\
\hline Overjet (mm) & -2.4 & 3.0 \\
\hline \multirow[t]{2}{*}{ Overbite (mm) } & 2.5 & 2.2 \\
\hline & \multicolumn{2}{|c|}{ Molar relationship } \\
\hline \multirow[t]{2}{*}{ Molar Relationship (mm) } & 5.7 & 7.3 \\
\hline & \multicolumn{2}{|c|}{ Hard and soft tissue profile } \\
\hline $\operatorname{NAP}\left({ }^{\circ}\right)$ & -3.4 & -1.5 \\
\hline Facial convexity* $\left(^{\circ}\right)$ & 172.0 & 170.5 \\
\hline H.NB* $\left(^{\circ}\right)$ & 4.5 & 7.5 \\
\hline Nasolabial angle* $\left({ }^{\circ}\right)$ & 100.0 & 100.0 \\
\hline Mentolabial fold* $\left(^{\circ}\right)$ & 124.0 & 117.0 \\
\hline
\end{tabular}

*Wits, distance between the perpendicular projections of landmarks $A$ and $B$ on the functional occlusal plane (AO-BO); ${ }^{2} \mathrm{FH}$,

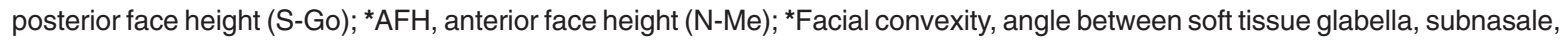
and pogonion; *H.NB, angle between Holdaway's soft tissue line and NB line; *Nasolabial angle, angle between pronasale, subnasale and labrale superior; *Mentolabial fold, angle between labrale inferior, point of greatest concavity between lower lip and soft tissue chin, and soft tissue pogonion.

and anterior diagonal elastic was used to aid in the correction of the midline, as necessary. After a good occlusal relationship was obtained, detailing and finishing procedures were then undertaken. When the fixed appliances were removed a Hawley retainer was placed in the maxillary arch and a canine to canine retainer was bonded in the mandibular arch.

\section{Treatment results}

The extraoral photographs show an improvement in the facial profile. The lower lip was retruded due to correction of the anterior cross-bite. The posttreatment 


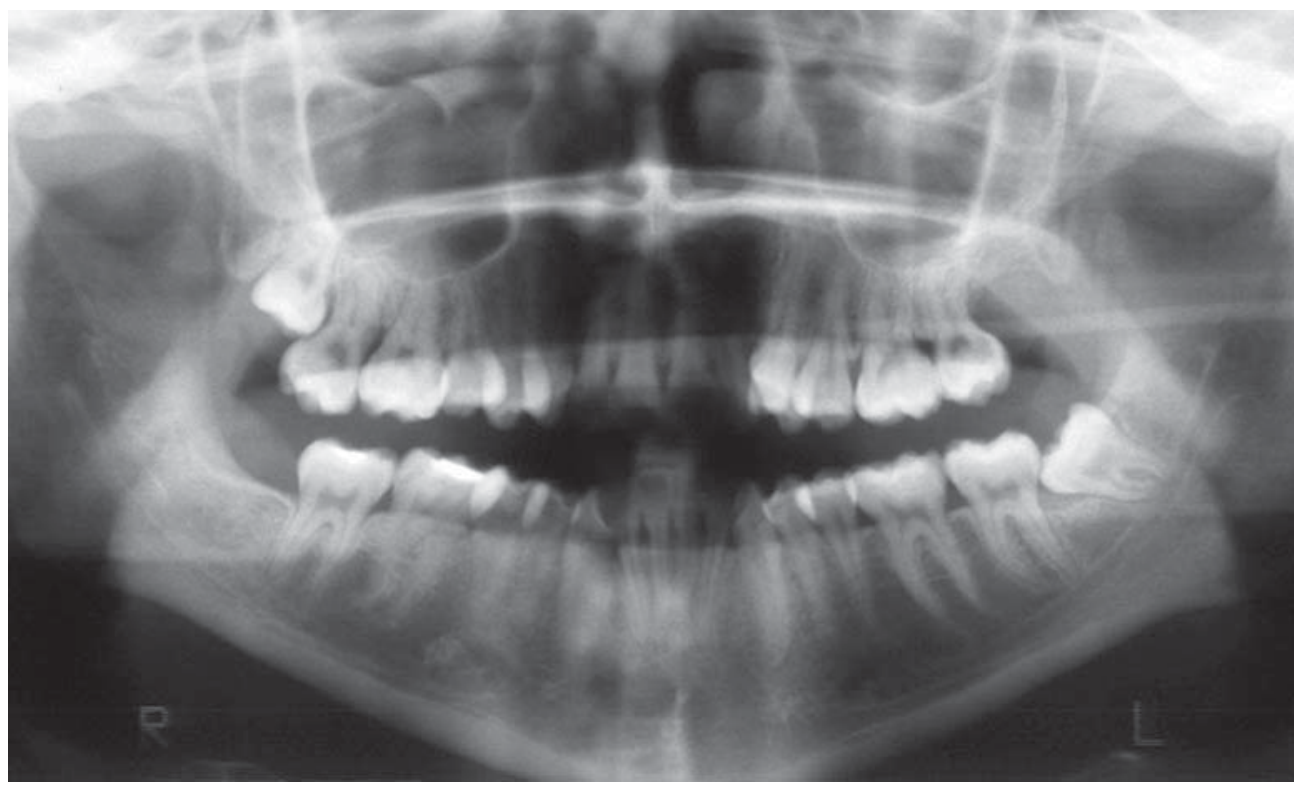

FIGURE 4- Pretreatment panoramic radiograph
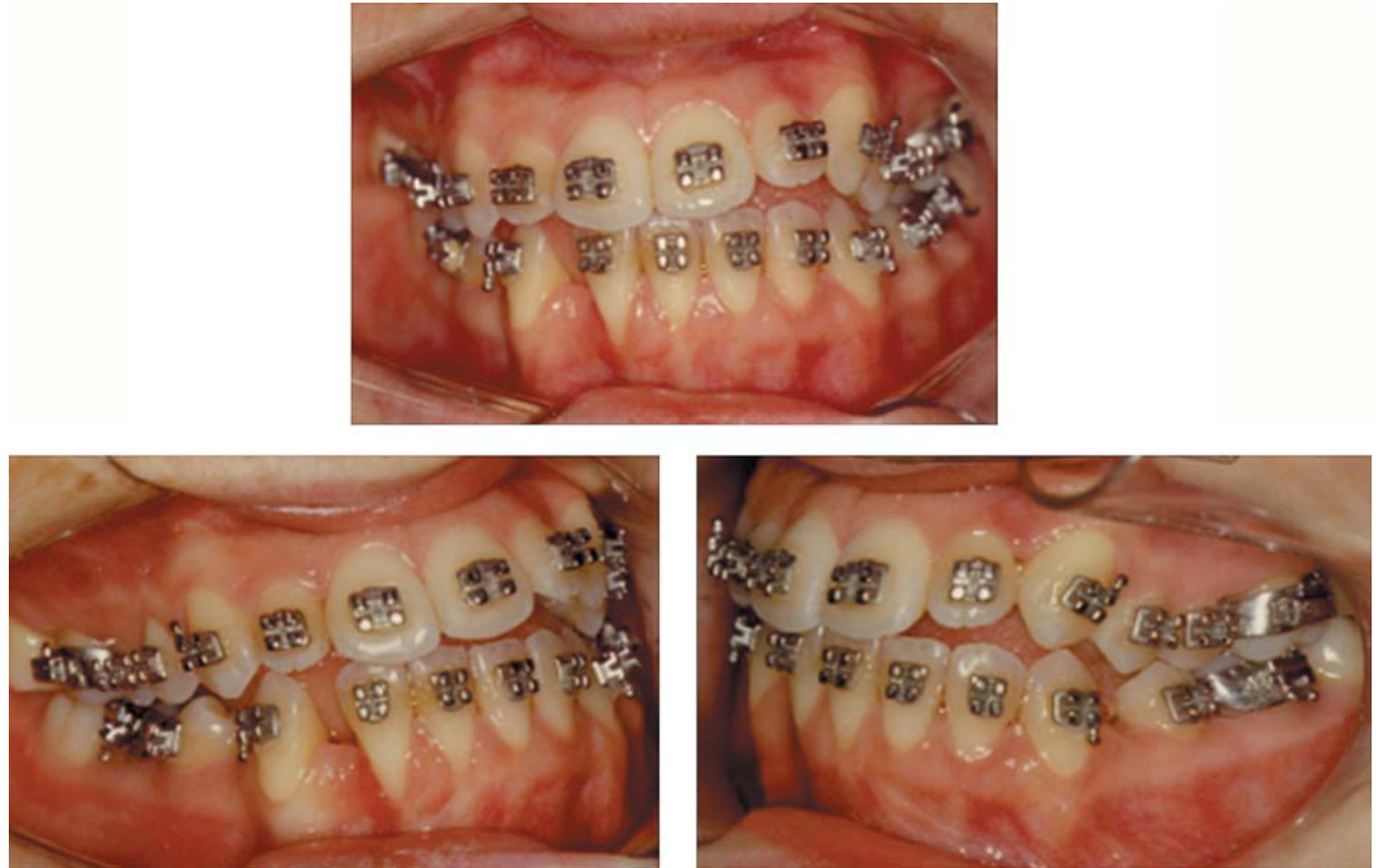

FIGURE 5- Correcting the anterior dental cross-bite after mandibular premolar extractions

intraoral photographs and dental casts show correct dental alignment, Class I canine relationship on both sides and a Class I molar relationship on the left side, and a Class III on the right, with normal overjet and overbite (Figures 6 and 7). There is only a slight maxillary to mandibular midline discrepancy that may have resulted from minor tooth size discrepancies between the right and left sides because the canines are in a Class I relationship bilaterally. There was an increase in gingival recession of the mandibular right central incisor. A periodontal 

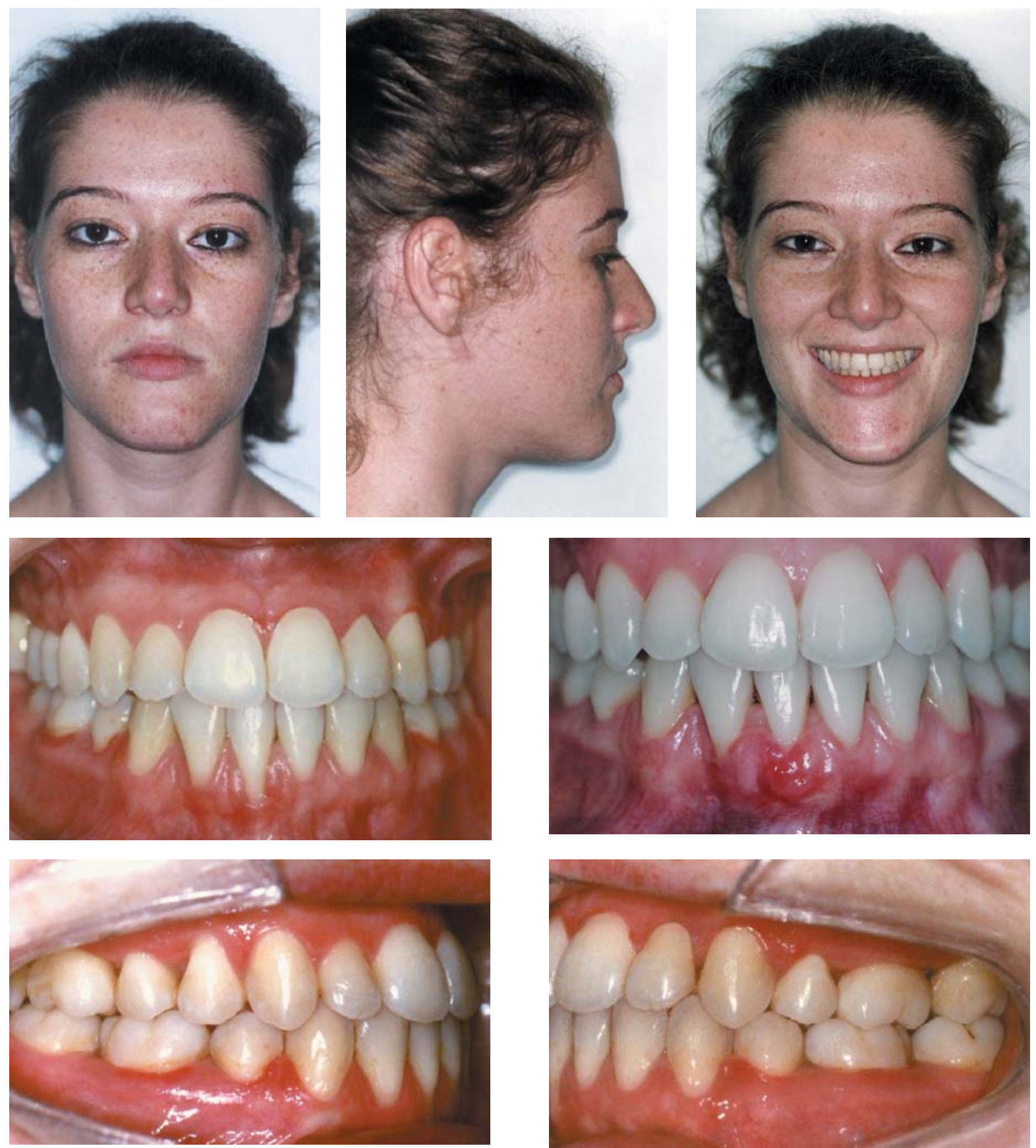

FIGURE 6- Posttreatment facial and intraoral photographs. A functional canine Class I occlusion with good overbite and overjet was achieved. The intraoral frontal photograph on the right shows the periodontal surgery at the mandibular right central incisor, a few days after the procedure (patient signed informed consent authorizing the publication of these pictures)

surgery later corrected this problem. The patient was satisfied with her teeth and profile. Good intercuspation, interproximal contacts, and reasonable root parallelism were achieved (Figure 8). The final cephalometric radiograph and superimposition show that the maxillary incisors were protruded, and the mandibular incisors were retracted and lingually tipped (Figures 9 and 10 and Table
1). The maxillary first molars remained in their initial anteroposterior position, and the mandibular first molars were uprighted (Figure 10). 

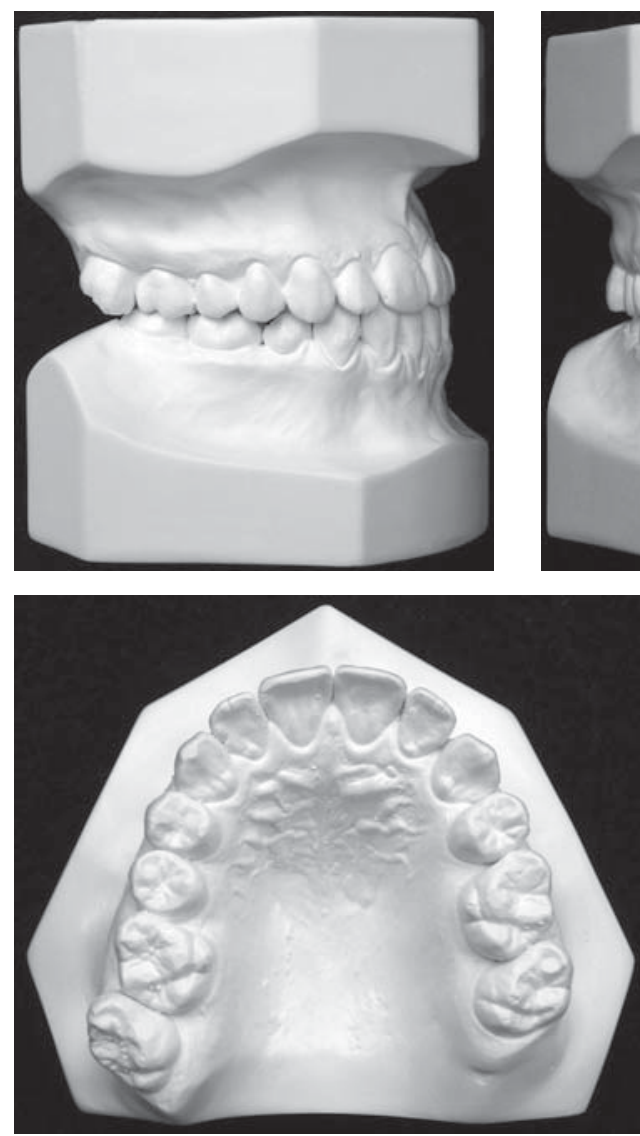

FIGURE 7- Posttreatment study models

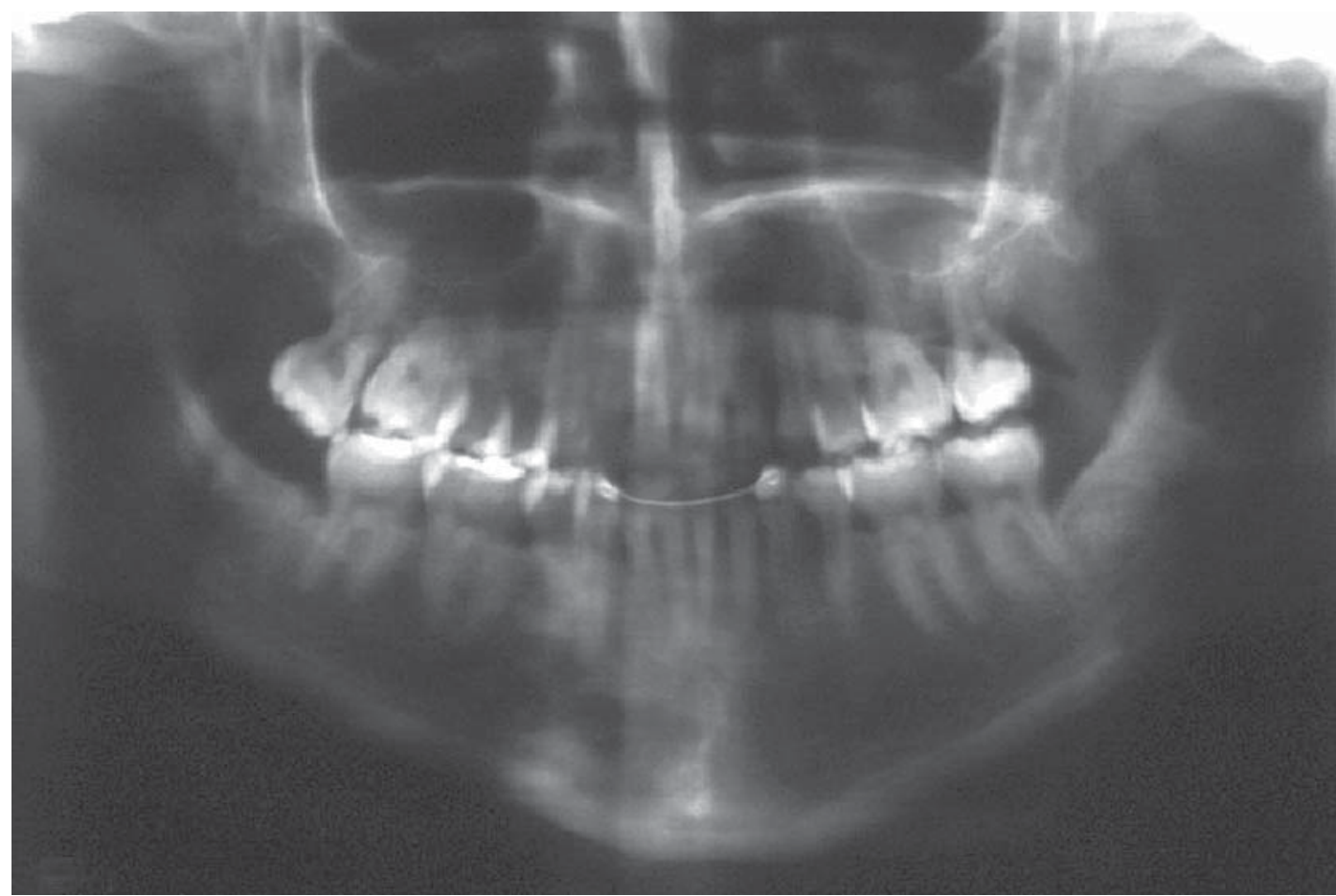

FIGURE 8- Posttreatment cephalometric radiograph
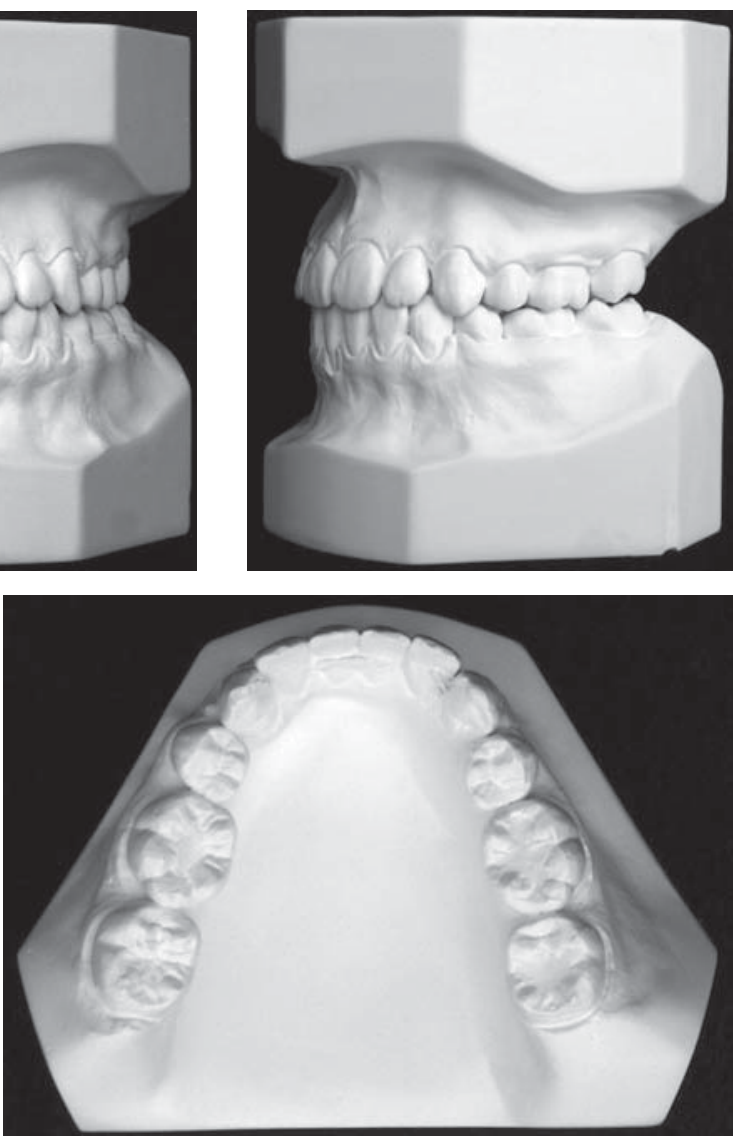

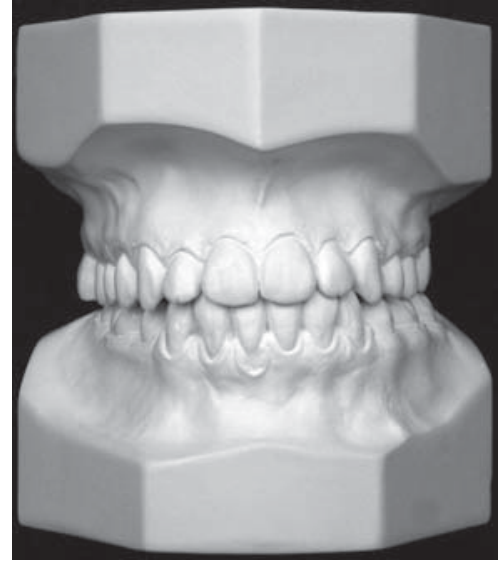




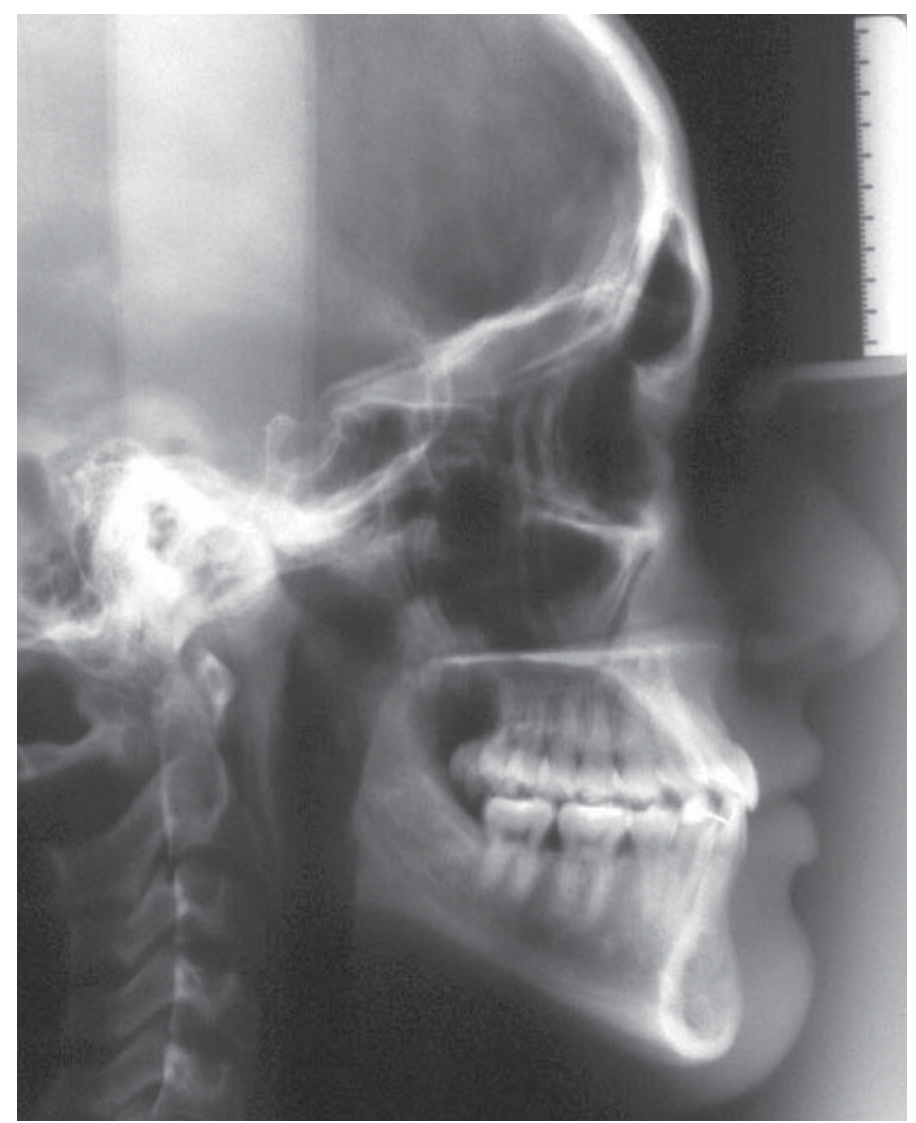

FIGURE 9- Posttreatment panoramic radiograph

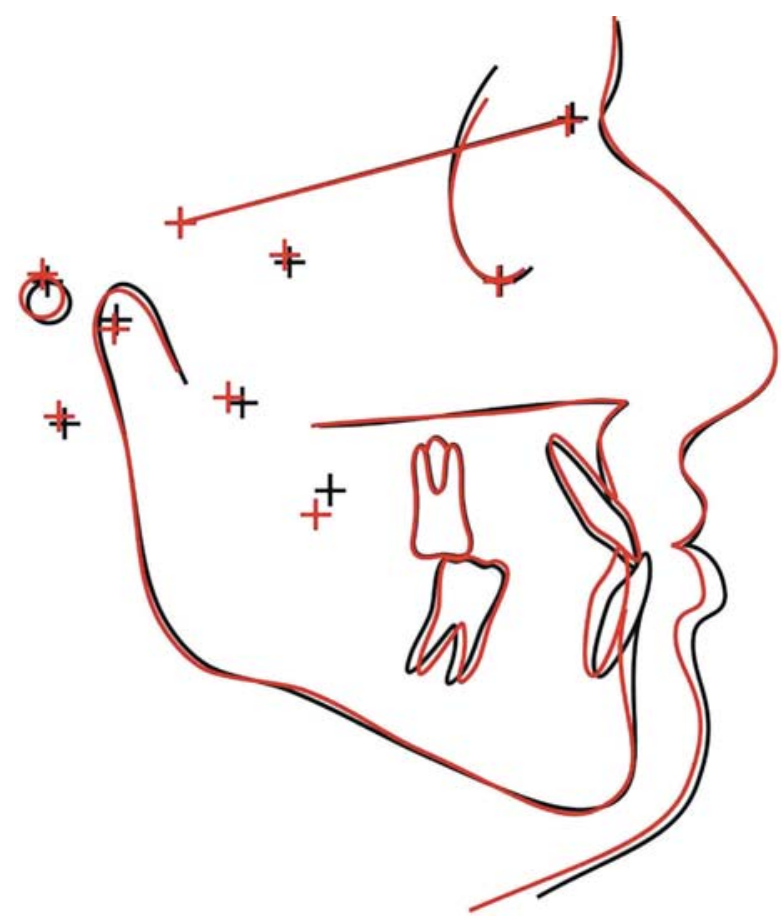

FIGURE 10- Superimposition of cephalometric tracings on SN at S 


\section{DISCUSSION}

At a glance, because of the malocclusion severity, it seems that this was a surgical case, as occurred with the first two professionals with whom the patient and parents consulted with, who had planned surgical approaches. However, with a closer examination one can realize that this is primarily a dental Class III subdivision malocclusion with very mild skeletal components as seen on the extraoral and intraoral photographs and on the lateral headfilm, despite an ANB of -2 and a Wits measurement of -7.2 (Figures 1 to 3 and Table 1). In the extraoral frontal view there is only a subclinical asymmetry that would very unlikely require any intervention $7,15,16,24$. The soft tissue profile also only demonstrates a slightly protruded lower lip in relation to the upper lip and to the facial contour. There is no noticeable mandibular skeletal prognathism, which is also confirmed in the lateral headfilm. Perhaps a surgically assisted maxillary expansion could be necessary in order to correct the bilateral posterior cross-bite. However, the patient's age was still within an age range susceptible to slow orthodontic maxillary expansion and could most probably respond favorably to this procedure. However, not even a rapid maxillary expansion was used to correct the posterior crossbite. Concerns with stability of the slow expansion obtained with wider archwires should not consist in an obstacle to this procedure because it has been shown that there is only slight differences in stability between slow and rapid maxillary expansion ${ }^{10}$. Therefore, after a more detailed analysis of the problem it becomes clear that since this was primarily a dental malocclusion it should be exclusively orthodontically corrected.

Initially, it appeared that extraction of 4 premolars would be the best treatment approach. This option would solve the mandibular and maxillary crowding and would produce a final occlusion with bilateral Class I molar and canine relationships ${ }^{8}$. However, attaining a Class I molar relationship on the original Class III side and a consequent coincidence of the maxillary and mandibular dental midlines would depend largely on patient compliance in using Class III and anterior diagonal intermaxillary elastics. This would create a greater dependence on patient compliance for a satisfactory result and therefore a greater risk for failure.

Another option would be to extract the four premolars and then surgically rotate and asymmetrically advance the maxilla on the right side. This would also be very acceptable. However, it would require an orthognathic surgical intervention with greater biological and financial costs.

Although similar studies to Class II subdivision malocclusions ${ }^{13,14}$ have not been conducted on Class III subdivision malocclusions, an analogous treatment planning rationale for Class II subdivision cases can be extrapolated to these cases. It has been shown that in most Class II subdivision malocclusions, the maxillary midline is usually coincident to the facial midplane $e^{7,16}$. However, the mandibular midline is usually displaced toward the Class II side due to the posterior positioning of the mandibular first molar on this side ${ }^{3,16}$. In these cases, the best treatment option consists in the extraction of two maxillary premolars and one mandibular premolar on the Class I side if the patient's profile admits some retraction. The current patient presents the mandibular midline coincident to the midsagittal plane and the maxillary dental midline deviated to the right (due to technical problems, the frontal intraoral photograph does not exactly depicts this relationship). Therefore, an analogous approach to a Class II subdivision malocclusion could be applied here with the exception that two first premolars will be extracted in the mandibular arch and one premolar will be extracted on the Class I side of the maxillary arch. This will result in a Class I canine and molar relationships on the Class I side and Class III molar and Class I canine relationships on the Class III side, along with coincidence of the maxillary and mandibular dental midlines to each other and in relation to the midsagittal plane. There is also minimal need for Class III and anterior diagonal intermaxillary elastics, because the molars on the Class III side will remain in their initial positions and correction of the interdental midline deviation will be consequent to closure of the maxillary extraction space.

After treatment, the gingival recession on the labial surface of the right mandibular central incisor increased (Figure 6). The mandibular central incisors are especially susceptible to the development of gingival recession because the labial bony root coverage on these teeth is limited in thickness ${ }^{11}$. Mandibular incisors in crossbite or edge-toedge occlusion evidencing minimal attached gingiva can undergo unfavorable mucogingival recession, particularly if plaque accumulation or traumatic occlusal forces are present $^{12}$, which may have caused the initial recessions observed in this case. Incisor proclination or retroclination may increase fenestrations and dehiscences ${ }^{11}$. Therefore, it seems that tooth movement in this case was responsible for the increased gingival recession in this tooth. A gingival graft should have been performed on this site before orthodontic treatment to avoid increasing the recession ${ }^{19,20,23}$. Anyhow, a gingival graft was performed after 12 months and the recession was corrected, as shown on Figure 6. Besides, correction of the anterior crossbite and improvement of oral hygiene also helped to enhance periodontal health ${ }^{1,9,22}$.

\section{CONCLUSION}

Recognizing the true dentoalveolar and skeletal characteristics of a Class III malocclusion, especially its subdivision features, is essential for a more favorable treatment approach, which will simplify the orthodontic mechanics and require less patient compliance and treatment time. An asymmetric malocclusion will be better handled with an asymmetric extraction protocol. 


\section{REFERENCES}

1- al-Jasser N, Hashim H. Periodontal findings in cases of incisor crossbite. J Clin Pediatr Dent. 1995;19:285-7.

2-Alavi DG, BeGole EA, Schneider BJ. Facial and dental arch asymmetries in Class II subdivision malocclusion. Am J Orthod Dentofacial Orthop. 1988;93:38-46

3- Azevedo AR, Janson G, Henriques JF, Freitas MR. Evaluation of asymmetries between subjects with Class II subdivision and apparent facial asymmetry and those with normal occlusion. Am J Orthod Dentofacial Orthop. 2006;129:376-83.

4- Burstone CJ. Dr. Charles J. Burstone on the uses of the computer in orthodontic practice (part 1). J Clin Orthod. 1979;13:442-53

5- Cheney EA. The influence of dentofacial asymmetry upon treatment procedures. Am J Orthod. 1952;38:934-45.

6- Cheney EA. Dentofacial asymmetries and their clinical significance. Am J Orthod. 1961;47:814-29.

7- Cook JT. Asymmetry of the cranio-facial skeleton. Br J Orthod. $1980 ; 7: 33-8$

8- Dietrich TS. An American Board of Orthodontics case report. Am J Orthod Dentofacial Orthop. 1990;97:181-7.

9- Engelking G, Zachrisson BU. Effects of incisor repositioning on monkey periodontium after expansion through the cortical plate. Am J Orthod. 1982;82:23-32.

10- Fenderson FA, McNamara JA Jr, Baccetti T, Veith CJ. A long-term study on the expansion effects of the cervical-pull facebow with and without rapid maxillary expansion. Angle Orthod. 2004;74:439-49.

11- Fuhrmann RA, Frohberg U, Diedrich PR. Treatment prediction with three-dimensional computer tomographic skull models. Am J Orthod Dentofacial Orthop. 1994;106:156-60.

12- Geiger AM. Malocclusion as an etiologic factor in periodontal disease: a retrospective essay. Am J Orthod Dentofacial Orthop. 2001;120:112-5.

13- Janson G, Cruz KS, Woodside DG, Metaxas A, Freitas MR, Henriques JF. Dentoskeletal treatment changes in Class II subdivision malocclusions in submentovertex and posteroanterior radiographs. Am J Orthod Dentofacial Orthop. 2004;126:451-63.

14- Janson G, Dainesi EA, Henriques JF, Freitas MR, Lima KJ. Class II subdivision treatment success rate with symmetric and asymmetric extraction protocols. Am J Orthod Dentofacial Orthop. 2003;124:25764.

15- Janson G, Lima KJ, Woodside DG, Metaxas A, Freitas MR, Henriques JF. Class II subdivision malocclusion types and evaluation of their asymmetries. Am J Orthod Dentofacial Orthop. 2007;131:57-66.

16- Janson G, Metaxas A, Woodside DG, Freitas MR, Pinzan A. Threedimensional evaluation of skeletal and dental asymmetries in Class II subdivision malocclusions. Am J Orthod Dentofacial Orthop. 2001;119:406-18.

17- Janson G, Pereira ACJ, Dainesi EA, Freitas MR. Dental asymmetry and its implications in orthodontic treatment: a case report. Ortodontia. 1995;28:68-73.

18- Janson G, Woodside DG, Metaxas A, Henriques JF, Freitas MR. Orthodontic treatment of subdivision cases. World J Orthod. 2003;4:3646
19- Janson RRP, Janson MRP, Martins PF. Periodontal plastic surgical procedures previous to orthodontic movement. Odonto POPE. 1997;1:6470

20- Jones SP. The use of an autogenous free gingival graft in the combined orthodontic and periodontal management of a buccally ectopic maxillary canine. Br J Orthod. 1987;14:155-60.

21- Lewis PD. The deviated midline. Am J Orthod. 1976;70:601-16.

22- Manschot A. Orthodontics and inadequate oral hygiene compliance as a combined cause of localized gingival recession: a case report Quintessence Int. 1991;22:865-70.

23- Maynard JG Jr, Ochsenbein C. Mucogingival problems, prevalence and therapy in children. J Periodontol. 1975;46:543-52

24- Peck S, Peck L, Kataja M. Skeletal asymmetry in esthetically pleasing faces. Angle Orthod. 1991;61:43-8.

25- Rose JM, Sadowsky C, BeGole EA, Moles R. Mandibular skeletal and dental asymmetry in Class II subdivision malocclusions. Am J Orthod Dentofacial Orthop. 1994;105:489-95.

26- Wertz RA. Diagnosis and treatment planning of unilateral Class II malocclusions. Angle Orthod. 1975;45:85-94. 